\title{
PENGARUH KEPUASAN DAN KEPERCAYAAN PELANGGAN TERHADAP NIAT PEMBELIAN ULANG DI TOKO ONLINE
}

\author{
Ramli Akbar Alamsyah \\ Department Of Management FEB UMM \\ Email : ramli.alamsyah@gmail.com
}

\begin{abstract}
The research aims to examine the effect of customer satisfaction and trust on repurchase intention. Sample used 100 respondents taken by purpossive sampling technique of online shoping customer. Path analysis employed to examine the effect customer satisfaction and trust on repurchase intention. the result shows that satisfaction and customer satisfaction have a positive effect on repurchase intention, and trust was mediating the effect of customer satisfaction on repurchase intention.
\end{abstract}

Keywords: Customer satisfaction, Trust, and Repurchase intention

\section{PENDAHULUAN}

Persaingan bisnis yang semakin ketat di Indonesia maupun secara global saat ini terutama di bidang teknologi dan informasi perusahaan menengah maupun atas saling berlomba lomba untuk bersaing untuk meningkatkan daya jual produk mereka masing masing. Dengan mudahnya mengakses internet semua perusahaan hampir bahkan semuanya memanfaatkan moment ini untuk menarik konsumen lebih banyak (Ishak, 2012).

Pembelian dan penjualan barang dan jasa sangat erat kaitanyya dengan perilaku konsumen . Tentu sebagai konsumen, Anda tidak ingin salah membeli suatu produk atau $\mathrm{n}$ jasa. Perilaku konsumen merupakan hal-hal yang mendasari konsumen untuk membuat keputusan pembelian. Ketika memutuskan akan membeli suatu barang atau produk, tentu Anda sebagai konsumen selalu memikirkan terlebih dahulu barang yang akan anda beli. memikir. (Ardianto, 2013).

Tingkat kepuasan pelanggan terhadap produk yang di jual sangat penting bagi perusahaan. Menurut Philip Kotler dan Kevin Lane Keller (2007:177). Perasaan senang atau kecewa seseorang yang muncul setelah membandingkan kinerja (hasil) produk yang dipikirkan terhadap kinerja yang diharapkan itu merupakan kepuasan pelanggan. Memuaskan kebutuhan konsumen merupakan keinginan setiap perusahaan.

Perusahaan harus bisa membuat seorang konsumen atau pelanggan dapat menaruh kepercayaan terhadap perusahaan. Cara yang dilakukan perusahaan beragam seperti misalnya menawarkan sebuah produk yang bisa meyakinkan konsumen untuk melakukan keputusan pembelian, 
membuat desain website yang menarik, dan mencantumkan sebuah testimonial yang dapat meyakinkan konsumen tentang produk yang di tawarkan perusahaan. Perusahaan membentuk kepercayaan kepada konsumen agar dapat percaya dengan produk yang ditawarkan yang nantinya akan membuat konsumen untuk melakukan keputusan pembelian (Marpaung, 2011).

Konsep kepuasan konsumen merupakan hal yang penting bagi para manajer pemasaran dimana kepuasan konsumen dapat mendorong pembelian ulang (Prabowo, 2014). Pembelian ulang (repurchase) bersifat bervariasi tergantung dari tingkat ketahanannya (durabilty) suatu produk. Untuk produk yang tidak tahan lama (nondurables), pembelian kembali di artikan sebagai tindakan membeli lagi setelah pembelian pertama atau trial. Sedangakan untuk produk yang tahan lama (durables), diartikan sebagai kesediaan konsumen untuk membeli ulang atau paling tidak memberikan satu saran kepada orang lain untuk melakukan pembelian (Marpaung, 2011).

Belanja Online biasa juga dilakukan dengan mengunjungi toko Online melalui media internet untuk mencari, menawar atau membeli produk dengan niat membeli dan mendapatkan produk tersebut. (Lutfiana,2014). Online Shopping atau belanja Online via internet, adalah suatu proses pembelian barang atau jasa melalui internet, para pedagang telah berusaha membuat toko Online dan menjual produk kepada mereka yang sering menjelajahi dunia maya (Internet) melalui berbagai macam media sosial, blog, bahkan web (Alfatris, 2014). Fenomena yang terjadi saat ini yaitu, pada bisnis online tentu saja penjual tidak akan pernah tahu bagaimana respon dari konsumen, apakah senang dengan apa yang mereka beli. Apakah merasa puas dengan barang yang di beli, sebagai penjual tentunya tidak mengetahui bagaimana respon apa yang di dapatkan oleh konsumen. Penjual hanya menduga-duga, apakah kemungkinan akan membeli kembali produk yang di tawarkan atau tidak.

\section{TINJAUAN PUSTAKA}

Minat beli ulang merupakan bagian dari perilaku pembelian dimana didalam konteks minat beli ulang tersebut terdapat konsep loyalitas (Souderlund dan Vilgon, 1999). Niat beli didefinikasikan sebagai kemungkinan seorng konsumen untuk berminat membeli suatu produk tertentu yang dilihatnya. Menurut Dodds, Monroe, dan Grewal (1991)

Kepuasan pelanggan di definisikan sebagai semua sikap berkenaan dengan barang atau jasa setelah di terima dan di pakai, dengan kata lain bahwa kepuasan (satisfaction) adalah pilihan setelah evaluasi penilaian dari sebuah transaksi yang spesifik (Kotler, 2007). Dalam penelitianya berhasil membuktikan bahwa kepuasan pelanggan di tentukan oleh penilaian pelanggan terhadap kualitas pelayanan yang di berikan.

Kepusan pelanggan akan di pengaruhi oleh harapan, persepsi kinerja, dan penilaian atas kinerja prodik atau jasa yang di konsumsi. Terdapat korelasi positif yang kuat antara persepsi kinerja terhadap 
kepuasan pelanggan. (Fornell, dan lehman, 1992) Kepercayaan pelanggan didefinasikan sebagai kamauan rata-rata konsumen untuk mempercayakan kemampuan merek dalam menampilkan fungsinya (Moorman et al., 2002). Kepercayaan pelanggan merupakan kesediaan atau kemauan konsumen dalam menghadapi risiko yang berhubungan dengan merek yang akan di beli akan menghasilkan hasil yang positif dan menguntungkan (Lau dan Lee., 1999).

Berdasarkan tinjauan pustaka yang telah di kemukakan, maka kerangka pikir dalam penelitian ini dapat di lihat pada gambar sebagai berikut:

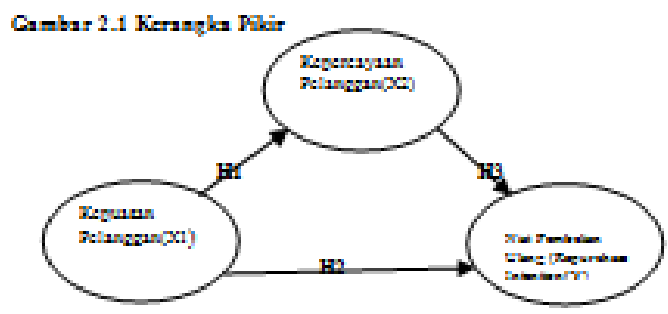

Gambar 1. Kerangka Pikir

Gambar di atas menjelaskan 3 variabel yang menjadi amatan studi yaitu Kepuasan Pelanggan, Kepercayaan Pelanggan, Niat Pembelian Ulang. Kepuasan pelanggan dan Kepercayaan pelanggan sebagai variabel independen. Niat pembelian ulang sebagai dependen.

Yang di maksut dengan Kepuasan pelanggan dan Kepercayaan pelanggan disini adalah konsumen merasakan kepuasan dan kepercayaan terhadap produk yang di tawarkan dan di jual oleh perusahaan Online . Produk di sini di artikan tidak hanya tertuju pada satu produk saja tetapi seluruh produk yang di jual dan di tawarkan perusahaan di media toko Online. Dan maksut dari niat pembelian ulang disini yaitu konsumen melakukan pembelian secara berulang-ulang kepada produk toko Online setelah konsumen mendapatkan kepuasan dan kepercayaan terhadap perushaan toko Online.

\section{METODE PENELITIAN}

Penelitian ini dilaksanakan di kota Malang. Jenis Penelitian ini menggunakan analisis deskriptif dengan pendekatan kuantitatif.

Kepuasan pelanggan adalah perasaan yang di rasakan pelanggan atas transaksi yang sudah di lakukan dan di terima dari toko online. Kepuasan terhadap produk di oprasionalkan dengan menggunakan indikator-indikator sebagai berikut (Wen, 2011 dan Casalo, 2011)

Puas dengan pengalaman belanja secara keseluruhan di toko Online, senang dengan pengalaman belanja secara keseluruhan di toko Online, layanan di toko Online sudah sesuai dengan harapan, saya berfikir sudah membuat keputusan yang tepat untuk berbelanja melalui website toko online.

Kepercayaan Pelanggan adalah keyakinan konsumen dalam pembelian produk di toko Online. Kepercayaan pelanggan dioprasionalkan dengan menggunakan indikator sebagai berikut (Wen, 2011, Ganguli, 2010 dan Zhang, 2011) :

Percaya Website toko online dapat melindungi privasi pelanggan, Penjual Online ini mampu menjalankan toko Online dengan baik, Percaya bahwa pemilik toko Online terpercaya, Percaya bahwa 
penjual toko online konsisten dalam pelayanan, Berdasarkan pengalaman, saya tidak berfikir akan terjadi kesalahan saat melakukan transaksi di toko online

Niat pembelian ulang adalah suatu kemungkinan untuk kembali melakukan pembelian di toko Online di masa yang akan datang. Niat pembelian ulang dioprasionalkan dengan menggunakan indikator (Wen, 2011 dan Prabowo 2014) :

Berniat untuk membeli kembali di toko online, Berbelanja online dengan sesering mungkin, Merekomendasikan orang lain untuk berbelanja Online.

\section{HASIL PENELITIAN DAN PEMBAHASAN}

Seluruh indikator dalam variabel penelitian ini mempunyai nilai $\mathrm{r}$ hitung dengan menggunakan Corrected Item Total Correlation lebih besar dari nilai $\mathrm{r}$ tabel yaitu 0,195. Nilai Korelasi dari seluruh indikator penelitian ini di atas 0,195 yang artinya semua indikator dinyatakan valid. maka dapat membuktikan bahwa butir pernyataan yang digunakan sebagai dalam kuisioner penelitian ini valid dan tepat digunakan untuk mengukur jawaban responden.

Uji reliabilitas semua variabel dalam penelitian ini mempunyai koefisien alpha $(a)>0,60$. Sehingga dapat memberikan jaminan tingkat konsistensi jawaban responden dan kuisioner dalam penelitian ini layak disebarkan kepada responden untuk dapat dijadikan sebagai instrumen dalam penelitian ini.

Berdasarkan hasil uji normalitas dengan menggunakan Kolmogrof Smirnov Test diperoleh hasil bahwa nilai signifikansi dari variabel kepuasan pelanggan sebesar 1,586 dan variabel kepercayaan pelanggan sebesar 1,187 dan keduanya lebih besar dari 0,05. Sehingga dapat disimpulkan bahwa data berdistribusi normal.

Hasil uji multikolinearitas dalam penelitian ini dapat dilihat dari nilai Tolerance kedua variabel bebas lebih besar dari 0,10 dan VIF kurang dari 10. Maka dapat disimpulkan tidak terjadi multikolinearitas dan model regresi dalam penelitian ini dikatakan baik.

Uji Heteroskedastisitas dalam penelitian ini menggunakan pengujian Glesjer. Hasil pengujian yang sudah di teliti bahwa bilah signifikan darri kepuasan sebesar 0,879 , kepercayaan sebesar 0,698 yang lebih besar dari 0,05 , maka dapat di simpulkan tidak terjadi multikolineritas antar variabel bebas. Berdasarkan hasil uji autokorelasi diperoleh hasil bahwa nilai Durbin-Watson (D-W) sebesar 1,640, nilai ini akan kita bandingkan dengan tabel DW dengan menggunakan derajat kepercayaan 5\%, Jumlah sampel 100 dan jumlah variabel bebas 2, maka di tabel Durbin Watson didapatkan nilai du 1,815 dan nilai dl 1,633. Jadi nilai DW 1,640 lebih besar dari batas (dl) 1,634 dan lebih kecil dari batas (du) yaitu 1,715 , maka dapat di simpulkan bahwa tidak ada kesimpulan pasti atau tidak dapat di simpulkan bahwa terdapat autokorelasi atau tidak.

Tabel 1. Hasil Analisis Data (Path Analisis)

\begin{tabular}{|c|c|c|c|}
\hline $\begin{array}{l}\text { Mode } \\
1\end{array}$ & R Square & $\begin{array}{c}\text { Adjuste } \\
\text { d R } \\
\text { Square }\end{array}$ & $\begin{array}{l}\text { Std. Error } \\
\text { of the } \\
\text { Estimate }\end{array}$ \\
\hline
\end{tabular}




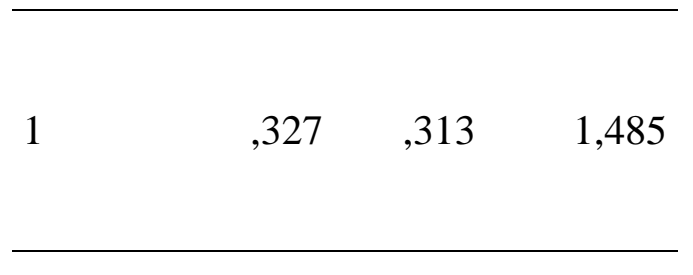

Dari tabel di atas, dapat di susun matriks koefisien jalur sebagai berikut : $b_{1} X_{1}=0,493$ dan $b_{2} X_{2}=0,119$, kerangka hubungan kausal empiris antara X1 dan X2 terhadap Y dapat dibuat melalui persamaan struktural sebagai berikut:

PERSAMAAN 1 :

$$
\begin{aligned}
\mathrm{Y}= & b_{1} X_{1}+b_{2} X_{2}+\mathrm{e} \\
= & 0,493 \times 1+0,119 \times 2+0,673 \\
& R^{2}=0,327 \\
\mathrm{e} & =1-R^{2} \\
& =1-0,327=0,673=67,3 \%
\end{aligned}
$$

$\begin{array}{cccc} & \text { Besarnya } & \text { kontribusi } & \text { kepuasan } \\ \text { (X1) } & \text { yang } & \text { secara } & \text { langsung }\end{array}$ mempengaruhi niat pembelian ulang (Y) adalah $0,493^{2}=0,243$ atau $24,3 \%$. Berarti bahwa variabel kepuasan berpengaruh secara langsung terhadap niat pembelian ulang sebesar $24,3 \%$.

Besarnya kontribusi kepercayaan pelanggan (X2) yang secara langsung mempengaruhi niat pembelian ulang (Y) adalah $0,119^{2}=0,014$ atau $1,4 \%$.

Besarnya kontribusi kepuasan (X1) dan kepercayaan pelanggan (X2) berpengaruh secara simulutan yang langsung mempengaruhi niat pembelian ulang (Y) adalah $0,327=$ $32,7 \%$. Sisanya sebesar $67,3 \%$ di pengaruhi oleh faktor-faktor lain yang tidak dapat di jelaskan dalam penelitian.

Tabel 2. Hasil analisis Jalur

\begin{tabular}{lcccc}
\hline $\begin{array}{l}\text { Mode } \\
1\end{array}$ & $\mathrm{R}$ & $\begin{array}{c}\mathrm{R} \\
\text { Squ } \\
\text { are }\end{array}$ & $\begin{array}{c}\text { Adjust } \\
\text { ed R } \\
\text { Square }\end{array}$ & $\begin{array}{c}\text { Std. } \\
\text { Error } \\
\text { of the } \\
\text { Estimat } \\
\text { e }\end{array}$ \\
\hline 1 &, $591^{\mathrm{a}}$ &, 349 &, 342 & 2,079 \\
\hline
\end{tabular}

a. Predictors: (Constant), kepuasan

Demikian tabel 2 yaitu penjelasan mengenai hasil analisis jalur yang didapatkan dalam penelitian ini. Berikut adalah tabel lanjutannya:

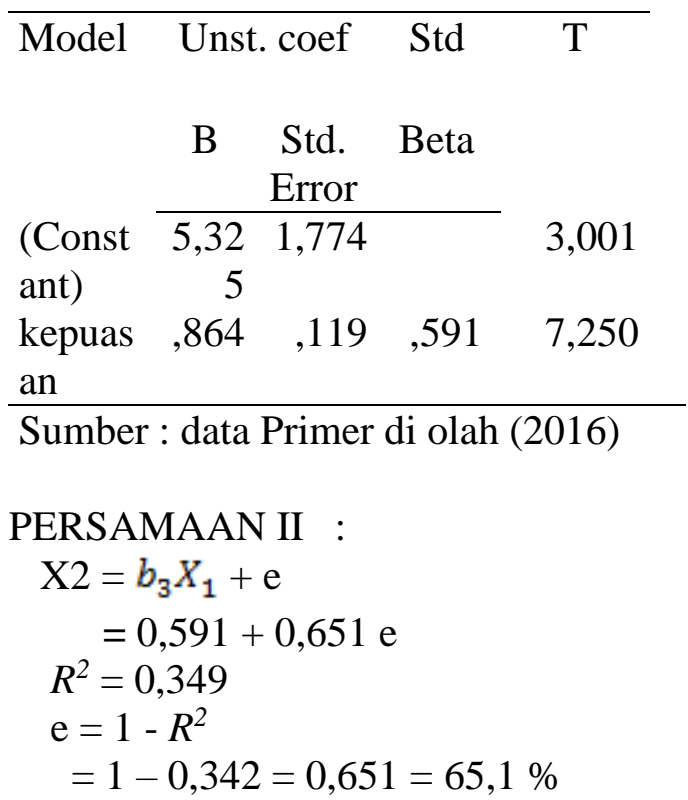

Besarnya kontribusi kepuasan pelanggan (X1) bila melalui kepercayaan pelanggan (X2) maka, mempengaruhi sebesar $0,591^{2}=$ $0,349=34,9 \%$

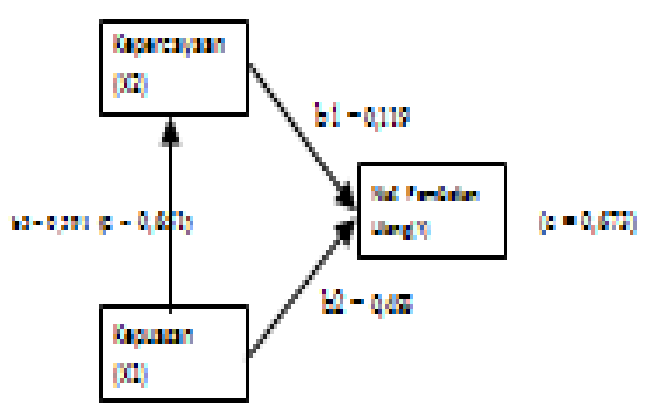


Keterangan :

$\mathrm{b}=$ besarnya kontribusi antar variabel

$\mathrm{e}=$ Std. Eror Pengujian sobel test diketahui bahwa kepercayaan memiliki kontribusi sebagai mediator dari kepuasan dan niat pembelian ulang. $\mathrm{Y}=b_{3} X_{1}+b_{2} X_{2}$ $=0,591+0,119=0,71$

Hasil tersebut menunjukkan bahwa pengaruh kepuasan terhadap niat pembelian ulang akan lebih besar apabila melalui mediator kepercayaan, dibandingkan dengan pengaruh langsung kepuasan terhadap niat pembelian ulang tanpa melalui mediator kepercayaan. Hal ini menunjukkan bahwa kontribusi dari variabel kepercayaan berpengaruh positif. Nilai pengaruh kepuasan apabila melalui kepercayaan lebih besar dibandingkan dengan pengaruh langsung kepuasan pelanggan terhadap niat pembelian ulang.

\section{SIMPULAN}

Variabel Kepuasan signifikan terhadap kepercayaan pelanggan dengan indikator puas dengan pengalaman belanja, senang dengan pengalaman belanja, layanan yang sesuai dengan harapan, keputusan yang tepat untuk belanja di toko online. Jadi semakin puasnya pelanggan maka akan semakin percaya pelanggan terhadap toko online.

Variabel kepercayaan pelanggan signifikan terhadap niat pembelian ulang indikator dapat melindungi privasi, penjual dapat melakukan dengan baik, penjual terpercaya, konsisten dalam pelayanan, dan tidak berfikir akan terjadi kesalahan ketika berbelanja online. Ketika pelanggan percaya maka akan ada niatan pelanggan untuk melakukan pembelian ulang pada toko online.

Variabel Kepuasan pelanggan berpengaruh langsung terhadap niat pembelian ulang dengan indikator Berniat untuk membeli kembali, belanja sesering mungkin di toko online, merekomendasikan pada orang lain. Maka ketika pelanggan merasa puas maka mereka secara tidak langsung akan berniat untuk melakukan pembelian ulang. Responden juga mempersepsikan tinggi merekomendasikan orang lain yang artinya ketika mereka puas dengan keseluruhan yang dilakukan toko online.

\section{DAFTAR PUSTAKA}

Ardianto, Roesdian. 2013. Pengaruh kepuasan nasabah terhadap loyalitas nasabah yang di mediasi oleh kepercayaan nasabah pada bank BRI Syariah Surakarta.

Alfatris, T. D. (2014). Pengaruh harga, Promosi, Kualitas Produk, Dan Kepercayaan terhadap minat beli K-Pop Album Dengan Sistem Pre Order Secara Online.

Casalo, LV., C. Falvian, dan M. Guinaliu. 2011. The Generation of Trust in the Online Service and Product Distribution: The case of Spanish Electronic Commerce. Journal of Electronic Commerce Research, Vol 12, No 3.

Dodds, W. B., Monroe, K. B dan Grewal, D., (1991), "Effect of price, brand and 
storeinformation on buyers' product evaluations", Journal of Marketing Research,(3), hal 307-319.

Fornell, Claes (1992), “A National Customer Satisfaction Barometer : The Swedish Experience', Journal of marketing, Vol. 56, jan, p.621

Ganguly, Boudhayan 2010. The effects of website design on purchase intention in online shopping: the mediating role of trust and the moderating role culture. Journal of electronic business, Vol. 8, nos. 4/5, 2010.

Ishak, Asmai. 2012. Analisis

Kepuasan Pelanggan dalam Belanja Online; Sebua Studi Tentang Penyebab (Antecedents) dan konsekuensi (Consequent).

Kotler, Philip dan Kevin Lane Keller. 2007. Manajemen Pemasaran. Jilid 1.Alih bahasa oleh Bob Sabran.Edisi 13. Jakarta: Erlangga.

Lau, Geok Then and Sook Han Lee. (1999).

"Kepercayaan

Pelanggan terhadap merek terhadap pembelian ulang"

Luthfiana, R. (2014). Analisis Kualitas Pelayanan, Promosi dan hedonic Shopping Motives yang mempengaruhi Impluse Buying dalam pembelian Online.

Marpaung, 2011. Pengaruh Store Enviroment Pada niat pembelian ulang pada konsumen metro supermarket medan plasa.

Moorman, Christine dan Anne S. Minner (2002), "The Impact of Organizational Memory on New Product Performance and Creativity", Journal of Marketing Research, Vol. 34, Feb, p.91-106.

Prabowo, Hartiwi., 2014. Analisis Kepercayan dalam C2C $E$ Commerce terhadap keputusan pembelian dan dampaknya terhadap Repurchase pada Kaskus.

Soderlund, Magnus dan Mats Vilgon (1999), "Customer Satisfaction and Links to Customer Profitability : an Empirical Examination of the Association

Between Attitudes and Behavior", Working Paper Series in Business

Administration, No. 1.

Wen, Chao 2011. An integrated model for customer online repurchase intention, journal of Computer Information System.

Zboja, James j dan Clay M. Voorchees (2006), The Impact of brand trust and satisfaction on retailer Repurchase Intention.

Zhang, Yixiang 2011. Repurchase Intention in B2C E-commerce a Relationship Quality Perspective. Journal of Information dan Management 48 (2011) 192-200. 